\title{
Almeida Nogueira e a cadeira de Economia Política, na Faculdade de Direito (*)
}

\author{
Prof. Cardozo de Mello Neto
}

\begin{abstract}
Para os que ainda têm viva nos olhos aquela figura de porte varonil e cavalheiresco, de elegância de maneiras e atitudes, de voz todo doçura e gentileza que, por mais de vinte anos, percorreu as Arcadas ensinando Finanças e Economia Política, com o propósito permanente de levar a seus discípulos a convicção de que a matéria lecionada não sendo Direito, sem ela o Direito se esvasiava daquêle conteúdo social que o coloca no ápice das ciências, porque o faz a ciência da coexistência humana; para aquêles que, pelo seu amor a esta Casa, têm, por isso, no coração, um lugar que é dêle e de mais ninguém, por ter exumado a história da Academia, vale dizer a própria história do Brasil, que uma com outra se fundem; para quem, como eu, teve a ventura de ter sido seu discípulo, sem sonhar com o singular privilégio de vir um dia a sucedê-lo; para uns e outros - para tôdos nós - relembrar a personalidade de José Luis de Almeida Nogueira, ressaltando o sentido da orientação do curso desde o Visconde de Caravelas até hoje - é a homenagem que está a dever, pelo centenário de seu nascimento, a Faculdade de Direito de São Paulo àquêle que elevou, no Brasil, a cátedra de Economia Política à altura nunca dantes alcançada.
\end{abstract}

(*) Aula inaugural dos Cursos de $\mathbf{1 9 5 3}$ 
À abertura do "curso jurídico", em 1869, surgia, dentre a turma de trinta estudantes matriculados no $10^{\circ}$ ano, um moço que para logo se vai fazer notar, tanto pela maneira fidalga de tratar os colegas e os lentes, quanto pela dedicação aos estudos. Vinha, com 18 anos de idade, revestido de uma cultura superior à da sua época. Sabia bem : tudo quanto então se ensinava de verdade no curso de humanidades e o mais que aprendera, durante seis anos, em Paris e no Bananal, com sábios professores franceses.

“Aplicado aos estudos (a observação é a de um de seus mais autorizados biógrafos, o nosso Pedro Chaves), escravo de suas obrigações, foi Almeida Nogueira um estudante verdadeiramente notável, tirando sempre as melhores notas em seus exames e a de "distinção", desde que instituida pela reforma de 1871 ".

Orgulhoso de sua escola - a qual admirava antes mesmo de para ela entrar, e nas primícias de um amor, que o tempo veio a evidenciar seria constante e perpétuo, como a justiça, esta prevaleceu num incidente que amargurou seu coração de colega, mas deu a medida de um carater afirmado em tôda a sua vida acidentada e trabalhosa.

Até 1871, os estudantes sorteavam o ponto para a prova oral com 24 horas de antecedência. Abolido, no fim do ano, o regime, os estudantes se rebelaram. Almeida Nogueira e mais seis companheiros submeteram-se à lei e porisso sofreram a incompreensão dos colegas. Respeitou o ponto de vista da maioria, mas não se intimidou. "Realizados os "atos", em fevereiro seguinte, tudo voltou ì normalidade sem deixar ressentimentos que os nobres corações juvenis não abrigam por muito tempo" (Pedro Chaves).

Nascido numa nobre família de lavradores e políticos chefes do Bananal - José Luis se vê eleito deputado provincial, ainda estudante do $5 .^{\circ}$ ano.

Mas seu máximo desejo era ser lente de Direito. Para isso, necessário se tornava defender, antes, teses. Almeida Nogueira, logo após a formatura, submeteu-se à dura prova e a venceu. Ei-lo, doutor em direito, aos 23 anos de idade. 
Logo após, porém, como aconteceu com outros de igual porte, em tôdas as épocas, a vocação do magistério foi recalcada pelas seduções enganadoras da política - mulher caprichosa que, uma vez conhecida, nunca mais é abandonada.

E, desde então o vemos deputado provincial, por muitas legislaturas; em seguida, deputado geral, por dilatados anos, até que, alçando-se ao Poder, o Partido Liberal elege, pela compressão, uma Ciâmara unânime.

Tôdo o Partido Conservador sofre o ostracismo político.

Nêsse largo espaço de tempo, paralelamente à política, o jornalismo o atráe.

A República o encontra na direção do "Correio Paulistano", órgão do Partido Conservador. IComo tôdos seus chefes, adere à República e é mandado por São Paulo à Constituinte de 1891, juntamente como Rodrigues Alves, Antonio Prado e Rubião Junior - a elite conservadora, que formará, para sempre, a benefício do Brasil, ao lado dos "históricos" Prudenté de Moraes, Campios Salles, Martinho Prado, Bernardino de Campos e Moraes Barros.

A atuação parlamentar de Almeida Nogueira foi, então, como antes e depoís, de uma perfeita coerência com sua alta concepção da vida.

Tendo uma nítida noção da disciplina partidária que jamais quebrou, moveu-se, no entanto, dentro de sua grei, sòmente para alcançar o bem comum. Jamais se confinou no chamado interêsse partidário. Porisso nunca foi un: "chefe político". Era, sim, um pensador, um intelectual de espírito arejado, pronto a olhar com simpatia as coisas novas, não para sem exame adotá-las, mas buscando delas extrair a parte proveitosa à coletividade.

A observação, que ficou célebre, feita na assembléia geral, em 1875, pelo eminente Andrade Figueira (exatamente uma mentalidade antípoda da de Almeida Nogueira), marca sua trajetória na vida: "o jovem deputado por São Paulo é um conservador de idéias não conservadoras". 
Estava para sempre definido o homem social que se iria dedicar aos esportes, numa época em que era de mau gôsto dêles cuidar; o homem político que se insurgiria até contra a lei, mandada aplicar pelo poder público (o caso das Câmaras Municipais, ao fim do Império) porque aberrante do "princípio natural da autonomia municipal"; o "conservador" que estréia na Constituinte colocando a equitativa discriminação de rendas, entre a União e os Estados, como base essencial do "paralelismo da autonomia das unidades federadas e da soberania da Nação"; o político que, ainda aí, em meio à confusão doutrinária que reinava entre os constituintes, de envolta com o "apetite desordenado de federalismo" (Ruy), procura fortalecer o poder executivo da União, ao reservar a esta, íntegra, a defesa do território e, porisso, negava aos Estados a manutenção de fôrças policiais militares. E' o parlamentar que, mais tarde em pleno regime individualista, combate certo projeto de criação de imposto porque de efeitos mèramente fiscais, quando o imposto é uma instituição econômica, política e jưridica" e, assim, deve "obrigar o capital inerte a movimentar-se em proveito da coletividade e não permanecer como uma riqueza potencial que ameaça transformar-se num sequestro"

É, ainda e sempre, o jornalista de "espírito finamente educado e pronto na concepção e na fatura da escrita" (Wencesláo de Queirós), apto a traçar, com idêntica mestria, desde o artigo doutrinário até a crônica faceta.

Finalmente, é o diplomata da escolha do Barão do Rio Branco para a 4. ${ }^{\text {a }}$ Conferência Pan-Americana, em Buenos Aires, pelo reconhecimento da primazia de sua competência em matéria então virgem, de patentes de invenção e marcas de fábrica.

Eis a fisionomia intelectual do político, parlamentar e jurista que o govêrno provisório da República escolheu, em primeiro lugar, para lente da Academia, independente de concurso. 
Era, na verdade, uma consagração porque, lopo após, viriam as nomeações de Carvalho de Mendonça, Amâncio de Carvalho, Jesuino Cardozo de Mello, Herculano de Freitas, Campos de Toledo, Manoel Villaboim, Aureliano Coutinho, Pinto Ferraz, Miranda Azevedo, Oliveira Lima, Machado de Oliveira e Rocha Miranda. Uns, por motivos diversos, não permaneceram entre nós, como o insigne comercialista e o douto Campos de Toledo, que, ambos, após a posse, se exoneraram e Jesuino Cardozo que, inexplicàvelmente, nos deixou após três anos de brilhante magistério.

Outros, porém, ao lado de Almeida Nogueira assaltaram a primeira linha para permanecer ao lado dos maiores desta Casa, de todas as épocas. Foram Herculano de Freitas, Manoel Villaboim, Pinto Ferraz, Aureliano Coutinho e Amâncio de Carvalho.

Inicia-se a fase aurea da vida de José Luis de Almeida Nogueira. Ia fazer 40 anos e era lente da Academia. Das cadeiras 'vagas, a naturalmente indicada, pelos pendores de seus estudos, era a de "Ciência das Finanças e Contabilidade do Estado", do curso de Ciências Sociais, onde lecionou de 1891 a 1896. Mas, preferiu a de Économia Política para onde de imediato é transferido pela morte do Dr. Vieira de Carvalho. Nela permanece até falecer, em pleno vigor, no ano de 1914.

São 18 anos em que José Luis se reparte entre o largo de São Francisco, ainda o mesmo, e o pequeno largo Municipal - hoje a grande praça João Mendes -. Entre a Academia que aqui permanece, como marco, e o Senado Estadual que desapareceu, como edifício e corporação.

Interessante relembrar a vida de alguns de nossos mestres, nesses tempos tranquilos de S. Paulo e o muito que fizeram por terem podido casar o ensino do Direito à prática mais pura do regimen. Eram políticos que, no mesmo dia, ensinavam Direito e o mantinham vivo na legislação e no equilíbrio entre o Município e o Estado, por via de decisão irrecorrivel do "Recurso Municipal". 
Pronunciar-lhes o nome é definir uma época: Almeida Nogueira, Duarte de Azevedo, Dino Bueno, Brasílio dos Santos, Herculano de Freitas, Pinto Ferraz, Gabriel de Rezende, Aureliano de Gusmão, Alcântara Machado, Cândido Mota, Raphael Sampaio e Reynaldo Porchat.

A cadeira de Economia Política, nesta Faculdade, sempre esteve entregue a homens dedicados aos estudos de economia e finanças, na parte em que tais conhecimentos são indispensáveis ao desenvolvimento do fenômeno jurídicopolítico. Professores tôdos adeptos da escola clássica e por isso mesmo procurando incutir em seus discípulos a regra de não intervenção do Estado na ordem econômica.

Para isso, porém, careciam (e é o que cumpre relembrar) colocar, nítida e inconfundivelmente, a Economia no campo do Direito Público. Não importa que o fizessem com a preocupação de reduzir as funções do Estado à atividade jurídica. Mas, o certo é que, na consecução de seu desideratum, estudavam a produção, circulação e consumo da riqueza em função do Estado. Eram juristas, forrados de economistas e como tais, jamais encararam o fenomeno econômico isolado e sempre e só conjugado com o ato jurídico.

Assim foram Carneiro de Campos, o visconde de Caravelas, Couto Ferraz, o visconde do Bom-Retiro, Carrão, o grande esquecido (cujos serviços a S. Paulo, como seu representante no âmbito nacional, estão a exigir excepcional homenagem desta Casa) - tôdos políticos integrais, fascinados pelo bem comum.

Nenhum dêsses ensinou aquela "Economia Política pura" que inventou o "homo economicus", fantasia que emparelha com o estudo da economia de Robinson na ilha deserta.

Para Carneiro de Campos, o Adam Smith que transmitia, com rara eloquência, era aquêle rei dos clássicos que, 
no entanto, já admitia um mínimo de intervenção do Estado na ordem econômica e o Macleod do insigne Carrão era o daquêle genial inovador, que dava à moeda uma origem e sentido até agora não destruidos pelos modernos e às vezes complicados economistas, insulados muitos dêles em seus teoremas, como se possível fôra enquadrar o fenômeno humano da produção e circulação da riqueza dentro de uma fórmula matemática.

Nem êsses, nem o último antecessor de Almeida Nogueira, o concencioso Vieira de Carvalho - nobre advogado militante, que lecionou a cadeira baseado na esplêndida obra de Cossa - deixaram de dar a seus alunos a impressão de que a Economia Política, como sua própria denominação o indica, era matéria essencial num curso de Direito.

Dentro dêsse tradicional ambiente, surge Almeida Nogueira.

Surge para ser o primeiro.

Foi em pleno fastígio de sua vida intelectual que o conheci. Estávamos em 1904 e a matéria era lecionada no $4 .^{\circ}$ ano. Se, sob o ponto de vista didático, alguma cousa tínhamos perdido, pois já completávamos o curso de Direito. sem ter tido notícia do fenômeno econômico, estávamos, porém, maduros para acompanhar o mestre em suas inesqueciveis aulas dadas às 8 horas da manhã, quando, sendo inverno, a neblina que envolvia as Arcadas e o jardim do Riachuelo, chegava a penetrar na antiga sala $n .{ }^{\circ} 3$. Ainda o tenho na retina como se fôra hoje. Alto, de uma beleza máscula, impressionante, com os cadernos de notas nas mãos, tôdo êle distilava bondade. Conservo os meus cadernos de apontamentos, encadernados e perfeitos. A êsse tempo, não havia a praga das "postilas", nem o mestre tinha ainda publicado sua monumental obra. $\mathrm{E}$, como não se limitava a um compêndio (é uma lenda idiota a de que em seu curso seguia servilmente Macleod), mistér se tornava tomar notas, estudar, porque, ao contrário, no fim do 
ano mais vexado do que o próprio aluno, quase pedindo desculpas, o Dr. José Luis convidava o estudante a levantar-se. Era êsse, na época, o eufemismo da reprovação. Reli agora os meus cadernos que vão completar meio século. Muitas vezes as lições não conservam a ordem didática a que, talvez com excesso, se quis jungir posteriormente no "tratado", mas a argumentação é muito mais brilhante, mais viva e, circunstância interessante, mais jurídica, às vezes exclusivamente jurídica. Combatendo inúmeras definições de Economia Polática, sente-se que não é o economista que discorda do colega, mas é o advogado que disseca o argumento central do adversário. Tudo, porém, como se estivesse (a observação é de Wencesláo de Queirós) na tribuna parlamentar: "Irônico e frio na réplica, dessa frialdade de lâmina de Toledo, que deixa o opoente incomodado por verificar que o corte the foi dado com luvas de pelica. Essa ponta de ironia é, aliás, um dos traços característicos da personalidade de Almeida Nogueira, a despeito de sua extrema delicadeza"

Almeida Nogueira já, então, era o mais límpido, o mais autorizado divulgador da doutrina de Macleod, superior ao clássico Richelot.

Seu "curso didático de Economia Política ou Ciência do Valor", vindo a lume em 1913, o evidencia. Êle mesmo o proclama no "Prefácio": "Somos sectários da Escola inovadora de Macleod".

Mas, suas aulas e seus livros deixam claro que de Macleod aceitava e defendia sòmente os princípios econômicos pròpriamente ditos - enclausurados num conceito de Economia que girava em tôrno do fenômeno da troca. Ainda dentro dêsse chírculo de ferro, a doutrina passava pelo crivo de uma percuciante crítica e o Mestre se permitia discordar do conceito macleodiano: exemplo frisante - o da divergência sôbre a origem da moeda.

Em seguida, porém, é o homem d'Estado que reponta: “Năo devemos levar a extremas consequências $o$ princípio 
individualista, quando em conflito com os interêsses fundamentais da comunhão social. Tais interêsses, temo-los também como direitos da coletividade, oriundos da solidariedade humana".

E, indo ao cerne do assunto, adverte: "Se a produção da riqueza não é fenômeno que possa resultar do exclusivo esfôrço da atividade particular, mas antes da ação do indivíduo com a colaboração, aparente ou oculta da sociedade, não é lógico, nem equitativo, contestar-se a legitimidade da interferência do Estado nos fenômenos da distribuição, circulação e consumo das riquezas".

São afirmações que reconhecem a legitimidade da intervenção do Estado na Ordem Econômica, ao mesmo passo que lhe traçam as respectivas lindes: "A harmonia dos direitos da sociedade com a liberdade humana, e não menos os direitos da humanidade com a liberdade social".

Eram conceitos quase revolucionários em sua época e hoje constituem ponto pacífico entre os que, por uma concepção espiritual da vida, adversários irremovíveis do marxismo materialista, reconhecem a impossibilidade do retôrno ao Estado egoista, mero produtor de segurança e, porisso, procuram criar um ambiente moral - único capaz de encaminhar o mundo para o ideal do equilíbrio econômico, que está na equitativa distribuição dos frutos dá produção entre o trabalho e o capital.

É o desenvolvimento de um programa que nasceu com esta Academia, levado às culminâncias pela obra imperecivel do Mestre e resguardada por seus sucessores.

Dêsses, o imediato, Dario Ribeiro, entra, vitorioso, nesta Casa, com uma dissertaqão sôbre "Socialismo"; outro, o atual, conscio de sua futura missão, procura, com modéstia, traçar a esfera da "Ação Social do Estado" e, diante do espetáculo do Mundo, vai, em mais de trinta anos de curso, alargando-a quanto lhe parece necessário, no propósito, talvez utópico, mas sincero, de fazer compreender 
que, dentro do Estado de Direito, há fontes para ser mitigada a sêde de justiça econômica e ambiente para ser satisfeita a fome de bem-estar social, uma e outra acirradas pelo impressionante progresso material.

Por coincidência, esta homenagem pelo centenário de José Luis de Almeida Nogueira realiza-se no momento em que seu último sucessor se prepara para entregar, apenas sem desgaste do capital, à nova geração a preciosa herança da cátedra de Economia Política.

Conservá-la, aumentando-a, será a delicada missão do moço que, nascicio dentro do mundo transmudado, creia na perenidade do Direito e ame, como filho, a Faculdade de Direito de São Paulo. 